Technische

Universität

Berlin

\author{
Eva M. Heppke, Stefan Berendts, Martin Lerch
}

\title{
Crystal structure of mechanochemically synthesized Ag2CdSnS4
}

Open Access via institutional repository of Technische Universität Berlin

\section{Document type}

Journal article | Published version

(i. e. publisher-created published version, that has been (peer-) reviewed and copyedited; also known as:

Version of Record (VOR), Final Published Version)

This version is available at

https://doi.org/10.14279/depositonce-12526

\section{Citation details}

Heppke, E. M., Berendts, S., Lerch, M. (2020). Crystal structure of mechanochemically synthesized Ag2CdSnS4. In Zeitschrift für Naturforschung B (Vol. 75, Issue 4, pp. 393-402). Walter de Gruyter GmbH. https://doi.org/10.1515/znb-2020-0022 
Eva M. Heppke, Stefan Berendts and Martin Lerch*

\section{Crystal structure of mechanochemically synthesized $\mathrm{Ag}_{2} \mathrm{CdSnS}_{4}$}

https://doi.org/10.1515/znb-2020-0022

Received January 27, 2020; accepted February 20, 2020

\begin{abstract}
Ag}_{2} \mathrm{CdSnS}_{4}$ was synthesized by a two step mechanochemical synthesis route. From a detailed analysis of the observed reflections in the X-ray powder diffraction pattern, the crystal structure proposed in the literature (space group $\mathrm{Cmc}_{1}$ [E. Parthé, K. Yvon, R. H. Deitch, Acta Crystallogr. 1969, B25, 1164-1174; O. V. Parasyuk, I. D. Olekseyuk, L. V. Piskach, S. V. Volkov, V. I. Pekhnyo, J. Alloys Compd. 2005, 399, 173-177]) is questionable. Our structural investigations presented in this contribution point to the fact that $\mathrm{Ag}_{2} \mathrm{CdSnS}_{4}$ crystallizes in the monoclinic wurtzkesterite-type structure (space group $\mathrm{Pn}$ ). At around $T=200^{\circ} \mathrm{C}$, a phase transition to the orthorhombic wurtzstannite-type structure (space group $P m n 2_{1}$ ) is observed.
\end{abstract}

Keywords: $\mathrm{Ag}_{2} \mathrm{CdSnS}_{4}$; HT-XRD; mechanochemical synthesis; phase transition; Rietveld refinement.

Dedicated to: Professor Rüdiger Kniep on the Occasion of his $75^{\text {th }}$ birthday.

\section{Introduction}

$A_{2}{ }^{\mathrm{I}} B^{\mathrm{II}} C^{\mathrm{IV}} X_{4}\left(X^{2-}=\mathrm{S}\right.$, Se, Te $)$ compounds are semiconductors exhibiting either a cubic or a hexagonal diamondrelated structure [1-3]. The most prominent group of $A_{2}{ }^{\mathrm{I}} B^{\mathrm{II}} C^{\mathrm{IV}} X_{4}$ semiconductors are Cu-bearing compounds [4-9]. Among them, $\mathrm{Cu}_{2} \mathrm{ZnSnS}_{4}$ has gained much attention as a potential candidate for absorber layers in thin film solar cells [10-12]. Ag-containing compounds are more difficult to synthesize and less stable. Nevertheless, a few $A_{2}{ }^{\mathrm{I}} B^{\mathrm{II}} C^{\mathrm{IV}} X_{4}$ phases with $A=\mathrm{Ag}$ are known so

*Corresponding author: Martin Lerch, Institut für Chemie, Technische Universität Berlin, Straße des 17. Juni 135, 10623 Berlin, Germany, Fax:+493031479656, E-mail: martin.lerch@tu-berlin.de Eva M. Heppke and Stefan Berendts: Institut für Chemie, Technische Universität Berlin, Straße des 17. Juni 135, 10623 Berlin, Germany far [4, 13-19]. For most Ag compounds, a stannite- or wurtzstannite-/wurtzkesterite-type structure has been presented in the literature. However, there are some compounds that deviate from these two structures. For $\mathrm{Ag}_{2} \mathrm{CdSnS}_{4}$, the space group $\mathrm{Cmc2}_{1}$ is proposed which can be considered as a hexagonal diamond-/wurtzite-derived structure with a statistical distribution of $\mathrm{Ag}, \mathrm{Cd}$, and $\mathrm{Sn}$ on Wyckoff position $4 a$ with $(0,0.167,0.370)$; sulfur is located at another $4 a$ position with $(0,0.176,0.997)$ [4, 20]. The results of our investigations on the aforementioned compound indicate a different crystal structure. Due to additional reflections in the X-ray powder diffraction pattern of our synthesized sample, space group $\mathrm{Cmc2}_{1}$ can be excluded. $\mathrm{Ag}_{2} \mathrm{CdSnS}_{4}$ was synthesized via a mechanochemical process which has proven its suitability for the successful preparation of phase-pure and well crystallized quaternary $A_{2}{ }_{2} B^{\mathrm{II}} C^{\mathrm{IV}} S_{4}$ compounds such as $\mathrm{Cu}_{2} \mathrm{ZnSnS}_{4}$ [21]. The crystal structure of our mechanochemically prepared $\mathrm{Ag}_{2} \mathrm{CdSnS}_{4}$ has been determined using powder X-ray diffraction. Additionally, UV/Vis and DTA measurements were performed. Surprisingly, a phase transition at around $T=200^{\circ} \mathrm{C}$ could be observed and the crystal structures of both the high- and lowtemperature phases were investigated by in-situ XRD.

\section{Results and discussion}

The mechanochemical synthesis approach with a subsequent annealing step as described in the experimental section results in the formation of phase-pure and well crystallized $\mathrm{Ag}_{2} \mathrm{CdSnS}_{4}$. Phase composition was determined by EDX and combustion analysis and is in accordance with the theoretical one (Table 1). EDX mapping also confirmed a homogenous distribution of $\mathrm{Ag}, \mathrm{Cd}, \mathrm{Sn}$, and S in the individual particles (Fig. 1).

Interestingly, in the DTA curve of our $\mathrm{Ag}_{2} \mathrm{CdSnS}_{4}$ sample thermal effects were observed. An endothermic peak occurs in the heating process $\left(T_{\mathrm{p}}=\sim 205^{\circ} \mathrm{C}\right)$ and an exothermic one is observed during cooling $\left(T_{\mathrm{p}}=\sim 199^{\circ} \mathrm{C}\right)$. This points to a reversible phase transition at around $200^{\circ} \mathrm{C}$ (Fig. 2). The reversibility of the phase transition was also proven by in-situ X-ray diffraction. 
Table 1: Phase composition of $\mathrm{Ag}_{2} \mathrm{CdSnS}_{4}$ calculated from EDX data and sulfur content determined by elemental analysis.

\begin{tabular}{lrr}
\hline $\mathrm{Ag}_{2} \mathrm{CdSnS}_{4}$ & & \\
\hline & Ideal (wt.-\%) & Measured (wt.-\%) \\
\hline $\mathrm{Ag}$ & 37.5 & 36.4 \\
Cd & 19.5 & 20.7 \\
Sn & 20.6 & 21.2 \\
S (EDX) & 22.3 & 21.7 \\
S (EA) & 22.3 & 22.0 \\
\hline
\end{tabular}

\subsection{Structural relationship between hexagonal diamond and the wurtzstannite-/wurtzkesterite-type structure}

As it can be seen in the Bärnighausen tree [22, 23], elucidating the relationship between the hexagonal diamond (lonsdaleite) and the wurtzstannite-/wurtzkesterite-type structures (Fig. 3), space group $\mathrm{Cmc2}$, as a subgroup to that of the wurtzite-type structure, is proposed either for binary compounds as well as for compounds with a statistical distribution of their cations/anions on one position. For $\mathrm{Ag}_{2} \mathrm{CdSnS}_{4}$, space group $\mathrm{Cmc2}_{1}$ is mentioned in the literature with $\mathrm{Ag}, \mathrm{Cd}$, and $\mathrm{Sn}$ distributed statistically on the position $4 a$ with $(0,0.167,0.370)$ and $S$ on another $4 a$ position with $(0,0.176,0.997)[20]$.

Similar compounds containing silver either crystallize in cubic diamond/sphalerite-related structures such as the stannite- or kesterite-type structure (such as $\mathrm{Ag}_{2} \mathrm{Zn}$ $\mathrm{SnS}_{4}$ [14], $\mathrm{Ag}_{2} \mathrm{FeSnS}_{4}$ [13], $\mathrm{Ag}_{2} \mathrm{ZnGeS}_{4}$ [24]) or in crystal structures derived from the hexagonal diamond/wurtzite type providing non-equivalent positions for the cations/anions (the wurtzstannite-type structure (space group $P m n_{1}$ ) and its derivatives with space group $P n$ (wurtzkesteritetype structure) or Pna2). Compounds crystallizing in the wurtzstannite-type structure are $\mathrm{Ag}_{2} \mathrm{CdGeS}_{4}$ [4] and $\mathrm{Ag}_{2} \mathrm{HgSnS}_{4}$ [15], whereas $\mathrm{Ag}_{2} \mathrm{MnSnS}_{4}$ [18] and Si-bearing compounds such as $\mathrm{Ag}_{2} \mathrm{FeSiS}_{4}$ [16] and $\mathrm{Ag}_{2} \mathrm{ZnSiS}_{4}$ [17] crystallize in the wurtzkesterite-type structure. Due to the close structural relationships between these three structures, it can be quite difficult to distinguish between them when using conventional methods. For $\mathrm{Ag}_{2} \mathrm{CdGeS}_{4}$, two polymorphs have been reported exhibiting the space groups $P m n 2_{1}$ [4] and $P n a 2_{1}$ [25], respectively.

\subsection{The high-temperature phase of $\mathrm{Ag}_{2} \mathrm{CdSnS}_{4}$}

Starting with the high-temperature phase, it should be noted that an orthorhombic unit cell could be found by the Werner algorithm using the program WINXPOW 1.2 (STOE \& Cie GmbH, Darmstadt, Germany) [29] for the sample at $T=300^{\circ} \mathrm{C}$. The lattice parameters were refined to $a=8.2263 \AA, b=7.0655 \AA$, and $c=6.7051 \AA$ leaving no reflection behind. The volume of the unit cell was calculated to $389.7 \AA^{3}$. It should be mentioned that the lattice parameter $a$ given by the Werner algorithm is two times larger than that of the proposed crystal structure with space group $\mathrm{Cmc2}_{1}$ for $\mathrm{Ag}_{2} \mathrm{CdSnS}_{4}$ [4, 20]. Examples of $A_{2}{ }^{\mathrm{I}} B^{\mathrm{II}} C^{\mathrm{IV}} X_{4}$ compounds with a lattice parameter $a$ of around $8.23 \AA$ (and similar values for the lattice parameters $b$ and $c$ ) within the orthorhombic crystal system have also been described by other authors [15].

For the Rietveld refinement of the high-temperature phase space group $P m n 2_{1}$ (wurtzstannite-type structure)

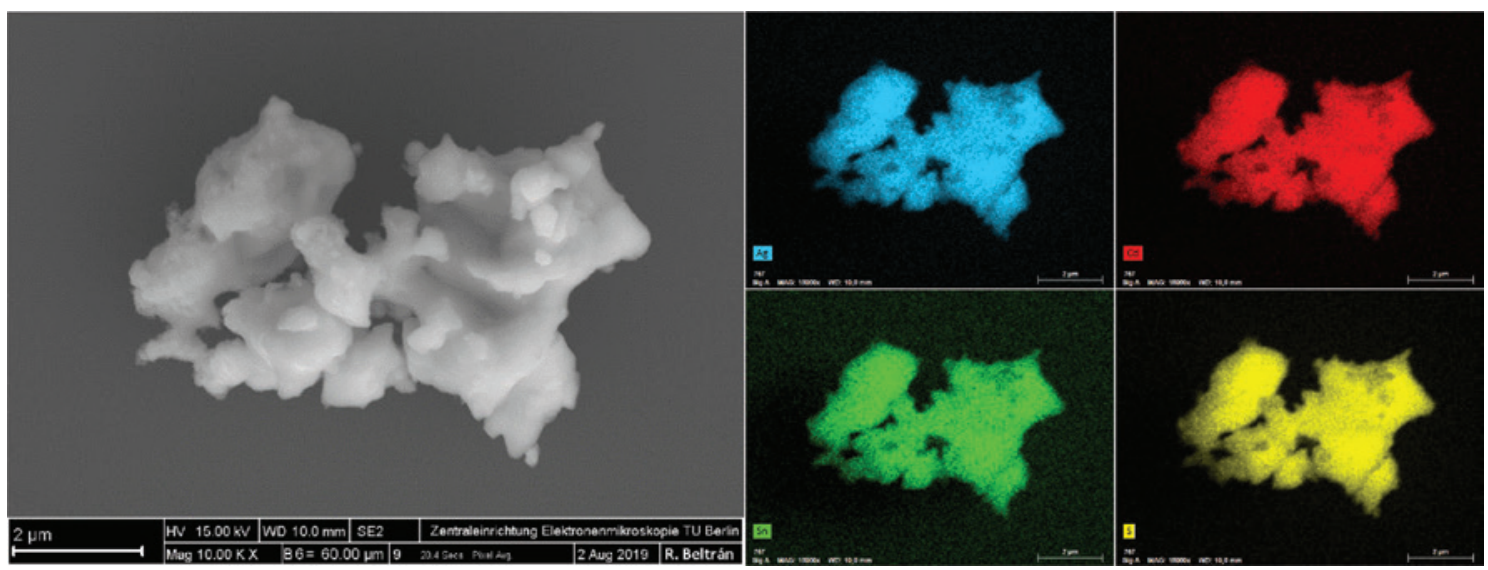

Fig. 1: $\mathrm{SEM}$ images of $\mathrm{Ag}_{2} \mathrm{CdSnS}_{4}$ particles and EDX mapping of homogenously distributed $\mathrm{Ag}$ (blue), $\mathrm{Cd}$ (red), $\mathrm{Sn}$ (green), and $\mathrm{S}$ (yellow) in the $\mathrm{Ag}_{2} \mathrm{CdSnS}_{4}$ particles. 


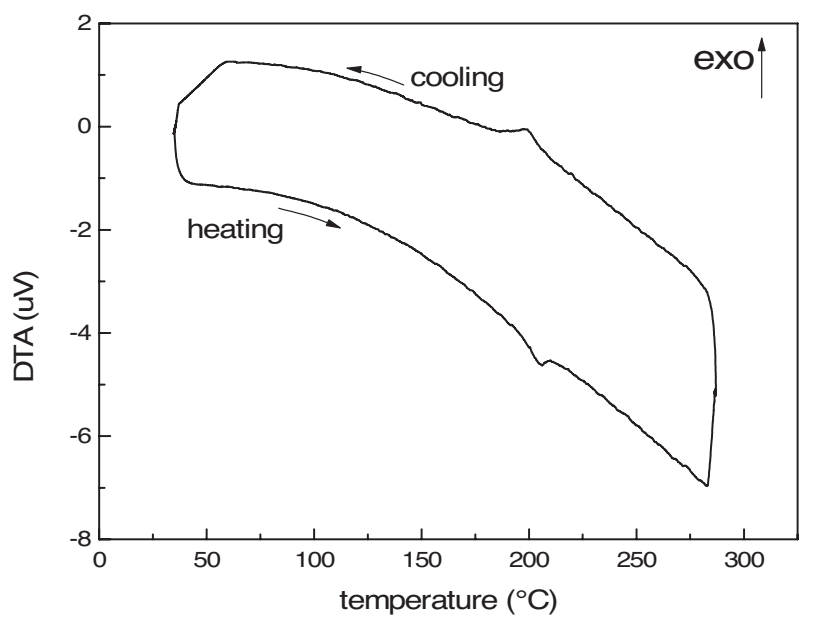

Fig. 2: DTA curve of $\mathrm{Ag}_{2} \mathrm{CdSnS}_{4}$ under nitrogen atmosphere.

is used. As depicted in Fig. 4, the experimental pattern is in good agreement with the theoretical one. Crystallographic details as well as atomic and structural parameters are listed in Tables 2 and 3. The Debye Waller factors of sulfur were set to a value of 1 and not refined, also the site occupation factors of all atoms. As Pmn $2_{1}$ is a polar space group and therefore possesses one origin-free direction (the $z$ direction), the $z$ parameter of the Ag atom position was fixed. As Ag, Cd, and Sn are not distinguishable using conventional X-ray diffraction methods, the distribution of these cations in the wurtzstannite- (and also wurtzkesterite-) type structure was set to that of the related compounds described in the literature.

The wurtzstannite-type structure (space group Pmn2 ${ }_{1}$ ) of the high-temperature phase of $\mathrm{Ag}_{2} \mathrm{CdSnS}_{4}$ can be described as a hexagonal diamond/wurtzite-derived structure with a hexagonal closest packing of sulfur anions. $\mathrm{Ag}$ is located at a fourfold position whereas $\mathrm{Cd}$ and $\mathrm{Sn}$ occupy two non-equivalent twofold positions. Three crystallographically independent sulfur positions are present, where $\mathrm{S} 1$ is located on a fourfold position and S2 as well as $\mathrm{S} 3$ atoms occupy two twofold positions. Considering the honeycomb set-up, the wurtzstannite-type structure is built up of consecutive $\mathrm{Ag}$ and $\mathrm{Cd} / \mathrm{Sn}$ layers (in general: $A^{\mathrm{I}}$ and $B^{\mathrm{II}} / C^{\mathrm{IV}}$ layers). This is manifested in alternating layers of Ag-centered and $\mathrm{Cd} / \mathrm{Sn}$-centered polyhedra along the $b$ axis (Fig. 5). These alternating stacking sequence appears to be in line with that of the stannite type $[5,30]$, the analogous structure type derived from the cubic diamond/ sphalerite-type structure. All atoms in the wurtzstannitetype structure are surrounded tetrahedrally. Each cation is coordinated by two S1 atoms, one S2 atom, and one S3 atom. The sulfur atoms are coordinated by two Ag and one $\mathrm{Cd}$ atom as well as one $\mathrm{Sn}$ atom.

\subsection{The low-temperature phase of $\mathrm{Ag}_{2} \mathrm{CdSnS}_{4}$}

For the crystal structure determination of the lowtemperature phase, all four direct subgroups of $P m n 2_{1}$ $\left(P 2_{1}, P m, P n\right.$, and $\left.P n a 2_{1}\right)$ (Fig. 6) were considered and tested as refinement models. For example, the symmetry reduction from space group $P m n 2_{1}$ to $P n$ is expressed by the splitting of the fourfold $\mathrm{Ag}$ atom position $4 b$ into two non-equivalent twofold positions $2 a$. The atomic and lattice parameters for the refinements in the four subgroups were generated by the program TRANSTRU found on the Bilbao Crystallographic Server [31-33]. For the space groups $P n a 2_{1}$ and $P n$, we also used reported structural parameter of related compounds $[25,28]$ as starting values in the Rietveld refinements.

In the subgroups $P 2_{1}, P m$, and $P n a 2_{1}$ convergence problems occurred during the refinements (profile, atomic positions, Debye-Waller factors). However, a successful refinement was achieved in space group $P n$, the wurtzkesterite-type structure. The experimental diffraction pattern is in good agreement with the theoretical one (Fig. 7). Crystallographic details are summarized in Table 2; atomic and structural parameters are presented in Table 4. The Debye-Waller factors of the sulfur atoms were kept fixed at a value of 1 , and the site occupation factors were not refined. Space group $P n$ also belongs to the group of polar/origin-free space groups. This particular space group exhibits two origin-free directions $(x$ and $z$ ). For the refinement in $P n$, the $x$ and $z$ parameters of the Ag1 atom position were kept fixed to define the origin.

The low-temperature phase of $\mathrm{Ag}_{2} \mathrm{CdSnS}_{4}$ crystallizes in the space group $P n$ (wurtzkesterite-type structure) with $a=6.704, b=7.038, c=8.217 \AA$, and $\beta=90.16^{\circ}$. The wurtzkesterite-type structure can be derived from the hexagonal diamond structure and is composed of a hexagonal closest packed arrangement of the sulfur anions (Fig. 8). The crystal structure contains two independent Ag positions Ag1 and Ag2, one $\mathrm{Cd}$, and one Sn position where all cations are located on twofold positions. This setup occurs also for the anions with in total four independent sulfur positions on twofold positions. Keeping in mind the honeycomb set-up, alternating $\mathrm{Ag} / \mathrm{Cd}$ and $\mathrm{Ag} / \mathrm{Sn}$ layers (in general $A^{\mathrm{I}} / B^{\mathrm{II}}$ and $A^{\mathrm{I}} / C^{\mathrm{IV}}$ layers) are distinguishable which is analogous to the kesterite-type structure [5] derived from the cubic diamond structure. Interatomic $\mathrm{Ag}-\mathrm{S}$ distances range from 2.46(3) to 2.52(4) $\AA$ with an average of $2.50 \AA$ for Ag1-S and from 2.52(3) to 2.58(2) A with an average of $2.55 \AA$ for Ag2-S. The Ag-S bond lengths correlate quite well with those known from $\mathrm{Ag}_{2} \mathrm{CdGeS}_{4}(\mathrm{Ag}-\mathrm{S}$ : 2.52-2.57 $⿱$ ) [34] and are slightly smaller than those reported for $\mathrm{Ag}_{2} \mathrm{FeSiS}_{4}$ 


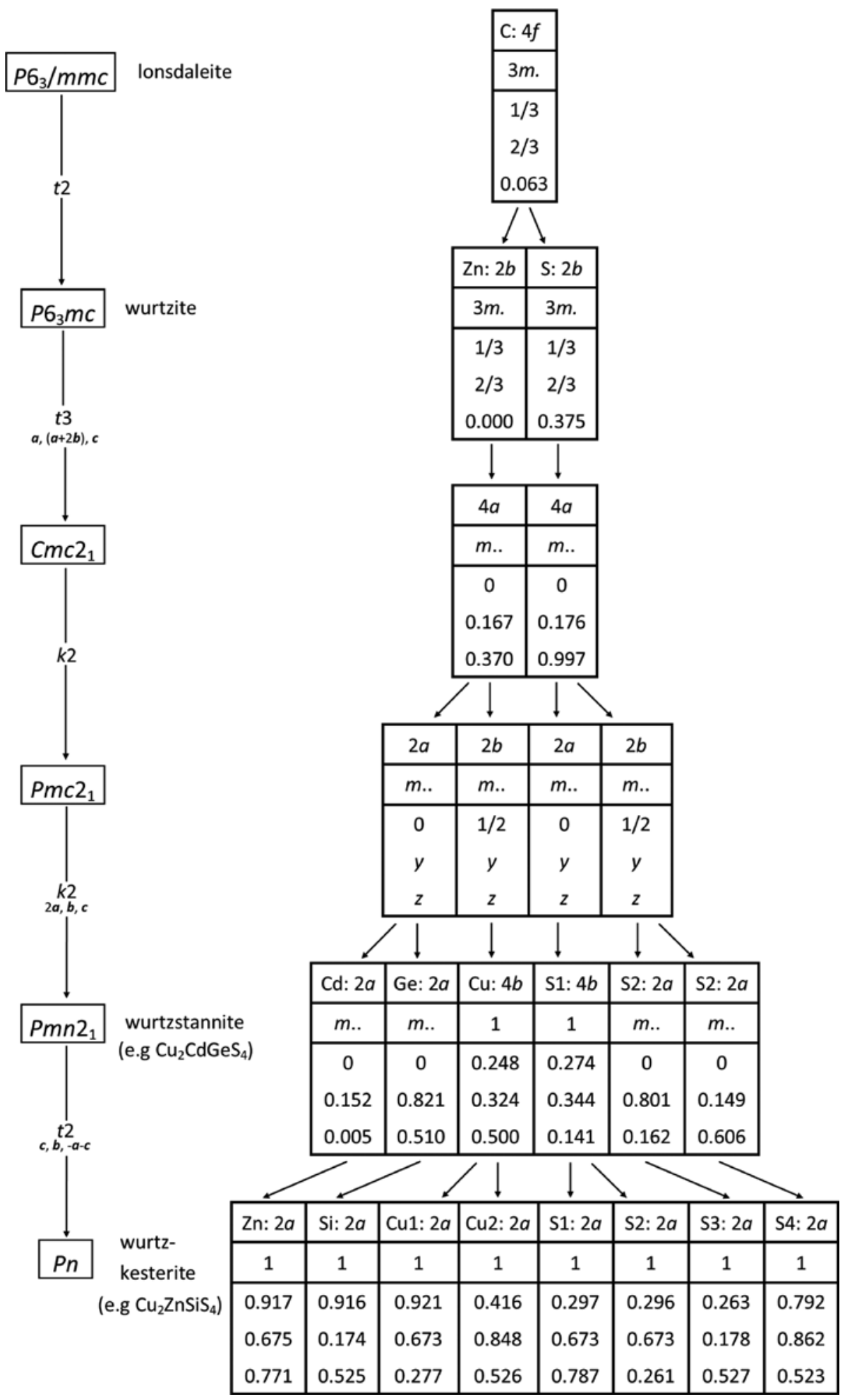

Fig. 3: Group-subgroup scheme (Bärnighausen formalism) for the group-theoretical relation between hexagonal diamond (lonsdaleite) and the wurtzstannite-/wurtzkesterite-type structure with data taken from [26] for lonsdaleite, [27] for wurtzite, [20] for space group $\mathrm{Cmc2}_{1}$, [4] for wurtzstannite-type $\mathrm{Cu}_{2} \mathrm{CdGeS}_{4}$, and [28] for wurtzkesterite-type $\mathrm{Cu}_{2} \mathrm{ZnSiS}_{4}$.

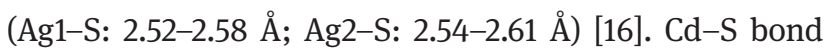
lengths range from 2.51(3) to 2.58(3) $\AA$ with an average of $2.55 \AA$ and are in good agreement with those found in
$\mathrm{Cu}_{2} \mathrm{CdGeS}_{4}(\mathrm{Cd}-\mathrm{S}: 2.51-2.60 \AA$ A $)[4]$ and $\mathrm{Ag}_{2} \mathrm{CdGeS}_{4}(\mathrm{Cd}-\mathrm{S}:$ 2.49-2.57 ̊) [34]. Interatomic Sn-S distances vary from 2.39(3) to 2.51(3) $\AA$ and are in average $2.43 \AA$ which is 


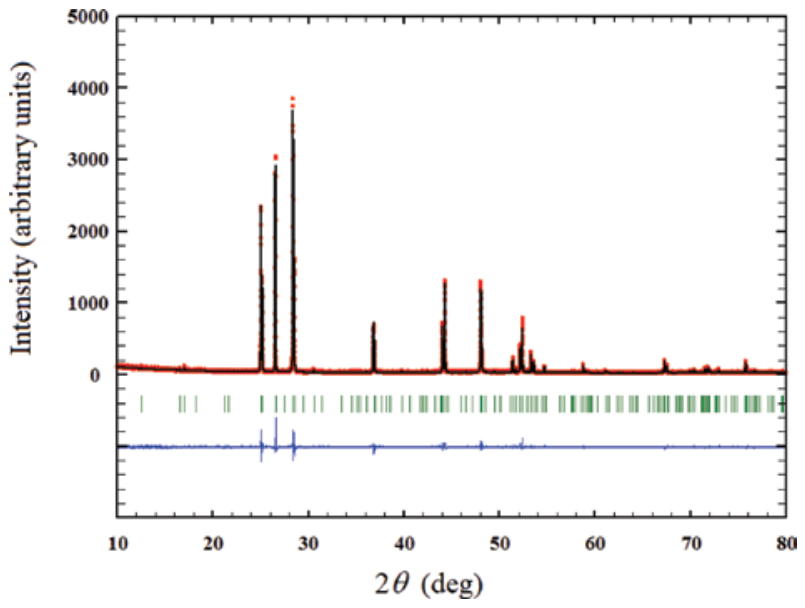

Fig. 4: X-ray diffraction pattern of the high-temperature phase (measured at $T=300^{\circ} \mathrm{C}$ ) of $\mathrm{Ag}_{2} \mathrm{CdSnS}_{4}$ with the results of the Rietveld refinement in space group $P m n 2_{1}$ (red: measured; black: calculated; blue: measured-calculated).

somewhat longer than those in $\mathrm{Li}_{2} \mathrm{CdSnS}_{4}$ (Sn-S: 2.38$2.39 \AA$ ) [35] and $\mathrm{Li}_{2} \mathrm{ZnSnS}_{4}$ (Sn-S: 2.35-2.42 ̊) [36].

\subsection{Stabilization of the high-temperature phase at room temperature}

The observed phase transition seems to be of first order. Consequently, it is no surprise that the stabilization of the high-temperature phase of $\mathrm{Ag}_{2} \mathrm{CdSnS}_{4}$ at room temperature was feasible by annealing the sample at $T=300^{\circ} \mathrm{C}$ for $3 \mathrm{~h}$ in an evacuated and closed silica tube in a vertically positioned tube furnace (Nabertherm RT 50-250/13; C450 controller) and subsequently quenching it in dry ice. Rietveld refinements were done in space group $P m n 2_{1}$ as well as in $P n$ and confirmed that the quenched sample crystallizes in the orthorhombic space group Pmn2. As expected, the difference of the residual values $R_{\text {wp }}$ between the space groups $P m n 2_{1}$ and $P n$ is not significant $\left(R_{\text {wp }}=10.9\right.$ for $P m n 2_{1}$ and $R_{\mathrm{wp}}=10.7$ for $P n$, respectively). Additionally, convergence problems occurred for the refinement in space group $P n$. The powder diffraction pattern of the stabilized high-temperature phase of $\mathrm{Ag}_{2} \mathrm{CdSnS}_{4}$ quenched to room temperature is shown in Fig. 9. Crystallographic details as well as atomic and structural parameters are presented in Tables 2 and 5. The refinement strategy was similar to that of the sample measured in-situ.

The interatomic $\mathrm{Ag}-\mathrm{S}$ distances in the quenched hightemperature phase vary from 2.505(12) to 2.521(15) $\AA$ with an average of $2.52 \AA$ and correlate well with the Ag1-S distances (2.46(3)-2.52(4) $\AA$ ) found in the low-temperature phase of $\mathrm{Ag}_{2} \mathrm{CdSnS}_{4}$. However, they are somewhat smaller than the Ag2-S distances (2.52(3)-2.58(2) $\AA$ ) reported for $\mathrm{Ag}_{2} \mathrm{CdGeS}_{4}$ (Ag-S: 2.52-2.57 ̊) [34] and $\mathrm{Ag}_{2} \mathrm{FeSiS}_{4}$ (Ag1-S:

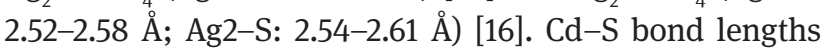
range from 2.531(17) to 2.59(3) $\AA$ with an average value of $2.56 \AA$. This correlates pretty well with reported $\mathrm{Cd}-\mathrm{S}$ distances for $\mathrm{Cu}_{2} \mathrm{CdGeS}_{4}(\mathrm{Cd}-\mathrm{S}: 2.51-2.60 \AA)$ [4] and $\mathrm{Ag}_{2} \mathrm{CdGeS}_{4}$ (Cd-S: 2.49-2.57 $\AA$ ) [34] as well with the ones in our

Table 2: Results of the refinements for the high- and low-temperature phases of $\mathrm{Ag}_{2} \mathrm{CdSnS}_{4}$ (standard deviations in parenthesis).

\begin{tabular}{|c|c|c|c|}
\hline & \multicolumn{3}{|l|}{$\mathrm{Ag}_{2} \mathrm{CdSnS}_{4}$} \\
\hline & High-temperature phase $T=300^{\circ} \mathrm{C}$ & Quenched high-temperature phase at r. t. & Low-temperature phase \\
\hline Crystal system & Orthorhombic & Orthorhombic & Monoclinic \\
\hline Space group & $P m n 2_{1}$ & $P_{m n 2_{1}}$ & $P n$ \\
\hline$Z$ & 2 & 2 & 2 \\
\hline Unit cell dimensions & $\begin{array}{l}a=8.2171(6) \AA \\
b=7.0641(5) \AA \\
c=6.7029(5) \AA\end{array}$ & $\begin{array}{l}a=8.2137(4) \AA \\
b=7.0403(4) \AA \\
c=6.7033(2) \AA\end{array}$ & $\begin{array}{l}a=6.7036(2) \AA \\
b=7.0375(3) \AA \\
c=8.2166(3) \AA \\
\beta=90.1577(9)^{\circ}\end{array}$ \\
\hline Cell volume, $\AA^{3}$ & $389.08(5)$ & $387.63(3)$ & $387.63(2)$ \\
\hline Calculated density, $\mathrm{g} \mathrm{cm}^{-3}$ & 4.91 & 4.93 & 4.93 \\
\hline Diffractometer & RIGAKU SmartLab 3 kW system & & \\
\hline Radiation & $\mathrm{Cu} K \alpha_{1}$ radiation & & \\
\hline Wavelength, $\AA$ & $\lambda=1.54060 \AA$ & & \\
\hline Number of refined parameters & 34 & 34 & 48 \\
\hline$R_{\mathrm{p}}$ & 0.096 & 0.081 & 0.100 \\
\hline$R_{\mathrm{wp}}$ & 0.128 & 0.109 & 0.138 \\
\hline$R_{\text {exp }}$ & 0.138 & 0.098 & 0.152 \\
\hline$R_{\text {Bragg }}$ & 0.049 & 0.049 & 0.050 \\
\hline$S^{-155}$ & 0.93 & 1.13 & 0.91 \\
\hline
\end{tabular}


Table 3: Refined atomic parameters for the high-temperature phase $\left(T=300^{\circ} \mathrm{C}\right.$ ) of $\mathrm{Ag}_{2} \mathrm{CdSnS}_{4}$ in space group $\mathrm{Pmn2}_{1}$ (standard deviations in parenthesis).

\begin{tabular}{llrrrrr}
\hline Atom & Wyckoff & $\boldsymbol{x}$ & $\boldsymbol{y}$ & $\boldsymbol{z}$ & s.o.f & $\boldsymbol{B}_{\text {iso }}\left(\AA^{2}\right)$ \\
\hline $\mathrm{Ag}$ & $4 b$ & $0.2543(7)$ & $0.3242(7)$ & $-0.01018^{\mathrm{a}}$ & 1 & $3.8(2)$ \\
$\mathrm{Cd}$ & $2 a$ & 0 & $0.8440(10)$ & $0.988(3)$ & 0.5 & $5.3(3)$ \\
$\mathrm{Sn}$ & $2 a$ & 0 & $0.1770(8)$ & $0.487(3)$ & 0.5 & $1.0(2)$ \\
$\mathrm{S} 1$ & $4 b$ & $0.239(2)$ & $0.336(2)$ & $0.378(3)$ & 1 & 1 \\
$\mathrm{~S} 2$ & $2 a$ & 0 & $0.180(4)$ & $0.834(3)$ & 0.5 & 1 \\
$\mathrm{~S} 3$ & $2 a$ & 0 & $0.855(4)$ & $0.363(4)$ & 0.5 & 1 \\
\hline
\end{tabular}

aFixed $z$ value.

low-temperature phase of $\mathrm{Ag}_{2} \mathrm{CdSnS}_{4}$ (2.51(3)-2.58(3) $\AA$ ). For the $\mathrm{Sn}-\mathrm{S}$ distances, the values vary from 2.39(3) to 2.491(17) A with an average of $2.45 \AA$ A. They are in agreement with those found in the low-temperature phase (2.39(3)2.51(3) $\AA$ ) and also with those reported for $\mathrm{Li}_{2} \mathrm{CdSnS}_{4}(\mathrm{Sn}-\mathrm{S}$ :

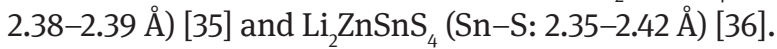

For the high- and the low-temperature phase of our $\mathrm{Ag}_{2} \mathrm{CdSnS}_{4}$ sample, additional refinements were undertaken in different space groups. These include the centrosymmetric space group Pnma as well as the non-centrosymmetric space group $P m c 2_{1}$. In addition, refinements in the triclinic crystal system have been performed. All refinements in these aforementioned space groups resulted in severe convergence problems. Consequently, we exclude all these space groups as possible candidates for $\mathrm{Ag}_{2} \mathrm{CdSnS}_{4}$.

Rietveld refinements in $\mathrm{Pmn}_{1}$ and $\mathrm{Pn}$ were done for all temperatures $\left(25-300^{\circ} \mathrm{C}, 25 \mathrm{~K}\right.$ steps $)$. The monoclinic angle $\beta$ was plotted against the temperature for the whole temperature range (black dots in Fig. 10). The plotted results point to the fact that $\beta$ abruptly becomes

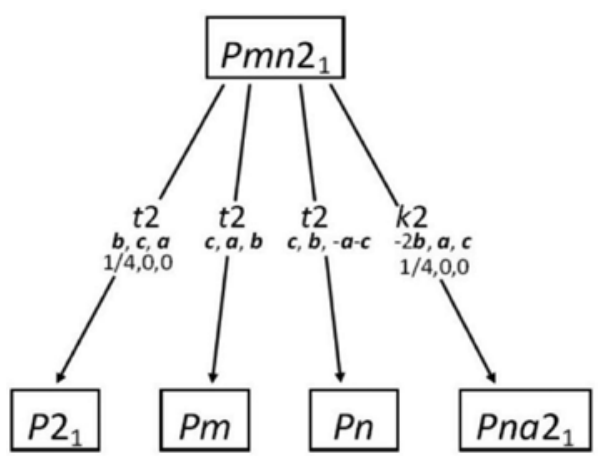

Fig. 6: Group-theoretical relation (Bärnighausen formalism) between space group $P m n 2_{1}$ (wurtzstannite-type structure) and its direct subgroups $P 2_{1}, P m, P n$, and $P n a 2_{1}$.

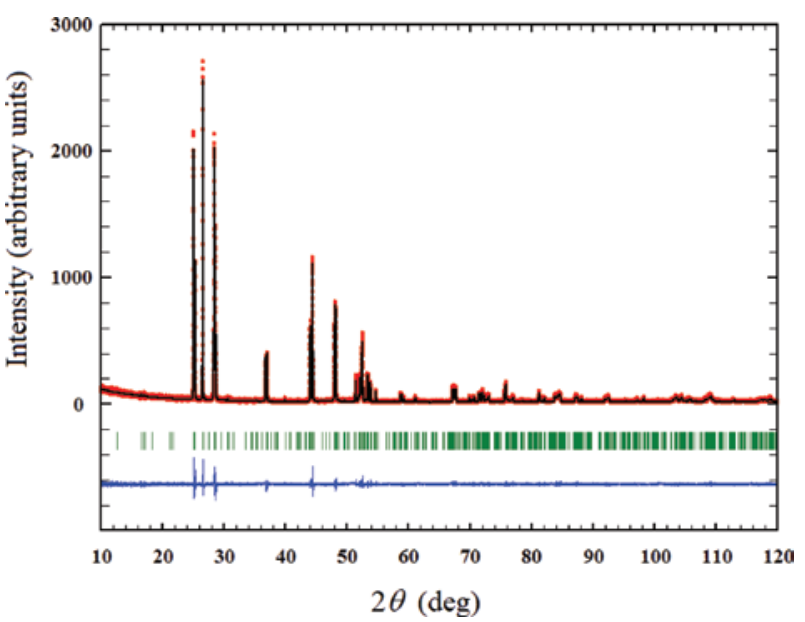

Fig. 7: X-ray diffraction pattern of the low-temperature phase (measured at $T=25^{\circ} \mathrm{C}$ ) of $\mathrm{Ag}_{2} \mathrm{CdSnS}_{4}$ with the results of the Rietveld refinement in space group $P n$ (red: measured; black: calculated; blue: measured-calculated).

$90^{\circ}$, the value of the orthorhombic high-temperature phase, at about $200^{\circ} \mathrm{C}$. This again indicates a first order
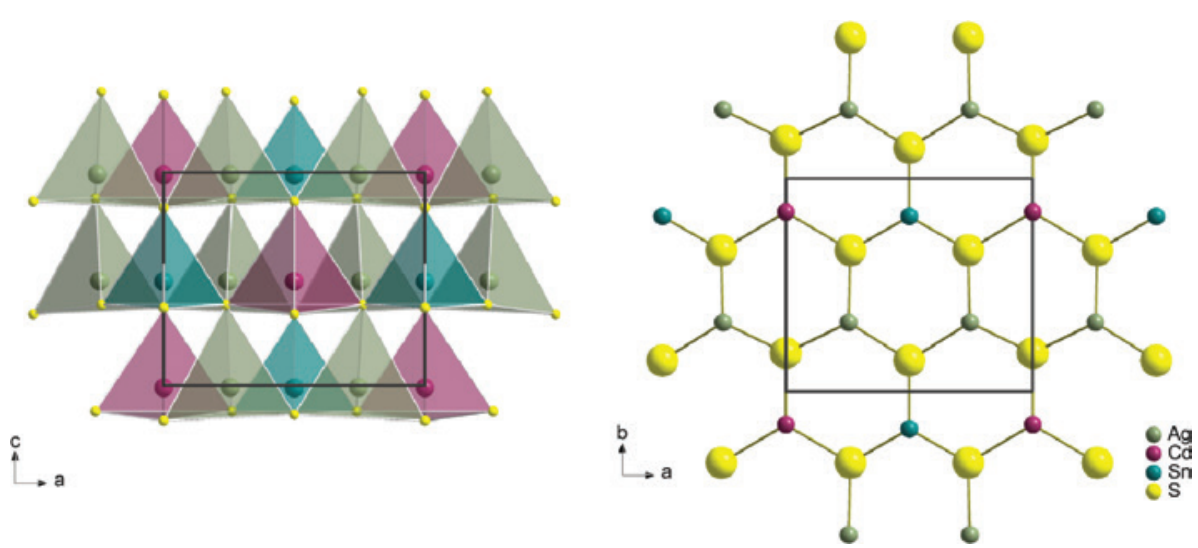

Fig. 5: Crystal structure of the high-temperature phase of $\mathrm{Ag}_{2} \mathrm{CdSnS}_{4}\left(\mathrm{Pmn2}_{1}\right)$ with cation-centered polyhedra viewed along the [010] direction (left) and the honeycomb set-up with stacking sequence of alternating $\mathrm{Ag}$ and $\mathrm{Cd} / \mathrm{Sn}$ layers viewed along the [001] direction (right). 
Table 4: Refined atomic parameters for the low-temperature phase of $\mathrm{Ag}_{2} \mathrm{CdSnS}_{4}\left(T=25^{\circ} \mathrm{C}\right)$ in space group $\mathrm{Pn}$ (standard deviations in parenthesis).

\begin{tabular}{llrrrrr}
\hline Atom & Wyckoff & $\boldsymbol{x}$ & $\boldsymbol{y}$ & $\boldsymbol{z}$ & s.o.f & $\boldsymbol{B}_{\text {iso }}\left(\AA^{2}\right)$ \\
\hline Ag1 & $2 a$ & $0.91670^{\mathrm{a}}$ & $0.675(4)$ & $0.27782^{\mathrm{a}}$ & 1 & $1.5(6)$ \\
Ag2 & $2 a$ & $0.407(3)$ & $0.8454(8)$ & $0.533(3)$ & 1 & $2.5(3)$ \\
Cd1 & $2 a$ & $0.913(2)$ & $0.674(4)$ & $0.773(3)$ & 1 & $1.99(6)$ \\
Sn1 & $2 a$ & $0.908(2)$ & $0.1759(7)$ & $0.523(2)$ & 1 & $0.22(13)$ \\
S1 & $2 a$ & $0.298(7)$ & $0.665(7)$ & $0.783(4)$ & 1 & 1 \\
S2 & $2 a$ & $0.284(6)$ & $0.669(8)$ & $0.278(5)$ & 1 & 1 \\
S3 & $2 a$ & $0.267(4)$ & $0.182(3)$ & $0.526(5)$ & 1 & 1 \\
S4 & $2 a$ & $0.791(4)$ & $0.851(3)$ & $0.521(4)$ & 1 & 1 \\
\hline
\end{tabular}

a Fixed $x$ and $z$ values.

transition from the wurtzkesterite-type structure to the wurtzstannite-type structure. The area around $200-225^{\circ} \mathrm{C}$ may be considered as two-phase region. The error bars at temperatures $\leq 200^{\circ} \mathrm{C}$ are smaller than those $>200^{\circ} \mathrm{C}$. For the refined cell volume, no significant jump in the region around $200^{\circ} \mathrm{C}$ can be observed (red squares in Fig. 10).

\subsection{UV/Vis spectroscopy}

The optical properties of $\mathrm{Ag}_{2} \mathrm{CdSnS}_{4}$ were measured in reflectance mode, and the optical band gaps were determined using the Tauc plot method [37, 38]. For the direct optical band gap a value of $E_{\mathrm{g}}=1.93 \mathrm{eV}$ was calculated whereas a narrower indirect optical band gap of $E_{\mathrm{g}}=1.82 \mathrm{eV}$ was obtained (Fig. 11). The color of our sample (black with violet accents) points to a direct optical band gap of $E_{\mathrm{g}}=1.93 \mathrm{eV}$ which is in good agreement with the experimentally determined band gap mentioned in literature [39].

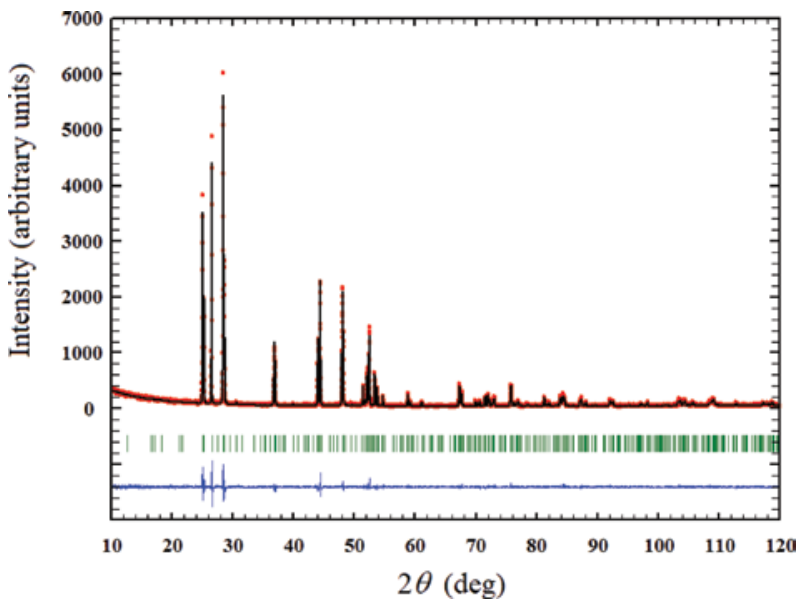

Fig. 9: X-ray diffraction pattern of the high-temperature phase of $\mathrm{Ag}_{2} \mathrm{CdSnS}_{4}$ stabilized at room temperature with the results of the Rietveld refinement in space group $P m n 2_{1}$ (red: measured; black: calculated; blue: measured-calculated).

\section{Conclusions}

Phase-pure and well crystallized $\mathrm{Ag}_{2} \mathrm{CdSnS}_{4}$ was synthesized by ball milling ( $350 \mathrm{rpm}, 5 \mathrm{~h}$ ) and subsequent annealing at $T=550^{\circ} \mathrm{C}$ under $\mathrm{H}_{2} \mathrm{~S}$ atmosphere for $2 \mathrm{~h}$ in a tube furnace. The observed reflections in the $\mathrm{X}$-ray powder diffraction pattern are not in agreement with the crystal structure proposed in literature (space group $\mathrm{Cmc2}_{1}$ ) where all cations are statistically distributed on one position. Structural investigations including Rietveld refinements using our mechanochemically prepared $\mathrm{Ag}_{2} \mathrm{CdSnS}_{4}$ sample point, in accordance to the calculations of Chen et al. [42], to the presence of the wurtzkesterite-type structure (space group $\mathrm{Pn}$ ) with an ordered arrangement of the cations. A reversible
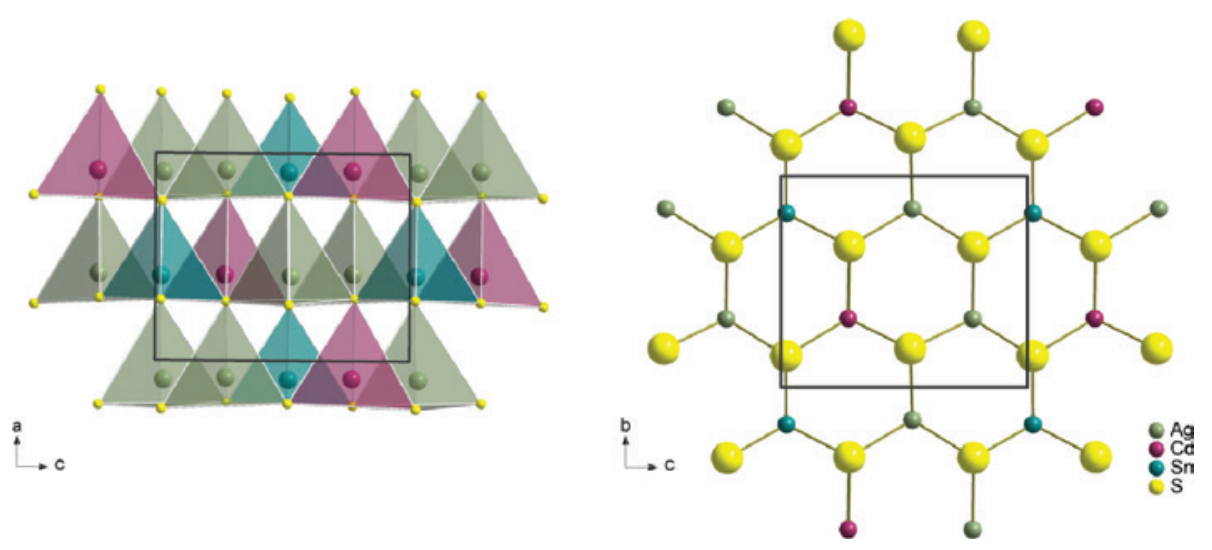

Fig. 8: Crystal structure of the low-temperature phase of $\mathrm{Ag}_{2} \mathrm{CdSnS}_{4}$ crystallizing in space group $P n$ with cation-centered polyhedra (view along the $[0 \overline{1} 0]$ direction, left) and the honeycomb set-up with a stacking sequence of alternating $\mathrm{Ag} / \mathrm{Cd}$ and $\mathrm{Ag} / \mathrm{Sn}$ layers viewed along the [100] direction. 
Table 5: Refined atomic parameters for the high-temperature phase of $\mathrm{Ag}_{2} \mathrm{CdSnS}_{4}$ in space group $P m n 2_{1}$ quenched to room temperature (standard deviations in parenthesis).

\begin{tabular}{llrrrrr}
\hline Atom & Wyckoff & $\boldsymbol{x}$ & $\boldsymbol{y}$ & $\boldsymbol{z}$ & s.o.f & $\boldsymbol{B}_{\text {iso }}\left(\AA^{2}\right)$ \\
\hline Ag1 & $4 b$ & $0.2532(9)$ & $0.3255(8)$ & $-0.00662^{\mathrm{a}}$ & 1 & $1.5(2)$ \\
Cd1 & $2 a$ & 0 & $0.8445(11)$ & $0.983(3)$ & 0.5 & $2.4(3)$ \\
Sn1 & $2 a$ & 0 & $0.1767(9)$ & $0.491(3)$ & 0.5 & $0.28(15)$ \\
S1 & $4 b$ & $0.251(3)$ & $0.337(3)$ & $0.368(5)$ & 1 & 1 \\
S2 & $2 a$ & 0 & $0.184(4)$ & $0.847(4)$ & 0.5 & 1 \\
S3 & $2 a$ & 0 & $0.851(4)$ & $0.369(6)$ & 0.5 & 1 \\
\hline
\end{tabular}

aFixed $z$ value.

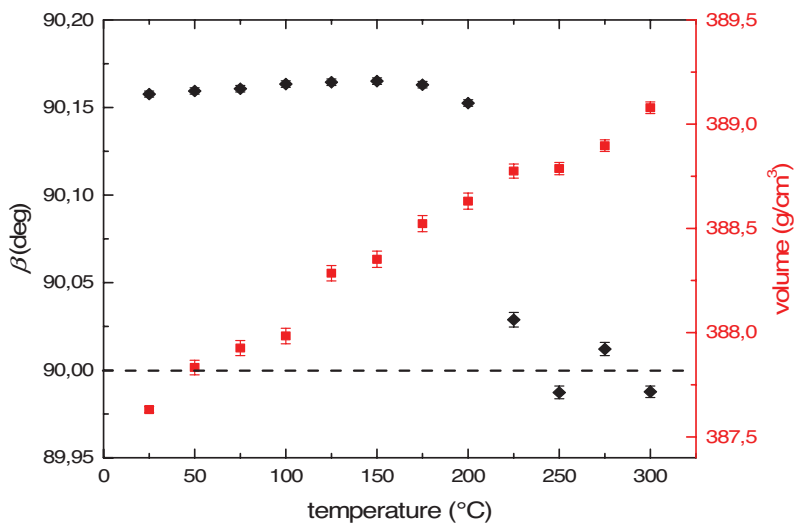

Fig. 10: Monoclinic angle $\beta$ and cell volume plotted against temperature (from Rietveld refinements in space group $P n$ for $\beta$ and from refinements in $P n\left(T \leq 200^{\circ} \mathrm{C}\right)$ and $P m n 2_{1}\left(T>200^{\circ} \mathrm{C}\right)$ for the cell volume).

first-order phase transition at around $200^{\circ} \mathrm{C}$ from a low-temperature wurtzkesterite- to a high-temperature wurtzstannite-type structure has been observed. Additionally, a direct optical band gap of $E_{\mathrm{g}}=1.93 \mathrm{eV}$, which is in agreement to that reported in the literature, was found. In the present work, the mechanochemical synthetic route was again successful for the preparation of phase-pure multinary sulfides. This particular way of synthesis appears to have a strong effect on the crystal structure of the resulting compounds. This may be an explanation for our different observations compared to the literature results presented in $[4,20]$.

\section{Experimental Section}

\subsection{Synthesis}

$\mathrm{Ag}_{2} \mathrm{CdSnS}_{4}$ was synthesized by ball milling in a highenergy planetary Mono Mill (Pulverisette 6, Fritsch, IdarOberstein, Germany), followed by an annealing step under an atmosphere of $\mathrm{H}_{2} \mathrm{~S}$. As starting materials $\mathrm{Ag}_{2} \mathrm{~S}$ (Schuchardt), CdS, SnS, and sulfur (Fluka, 99.99\%) were used which were filled in a $45 \mathrm{~mL}$ zirconia-made grinding beaker with 6 zirconia balls with a diameter of $15 \mathrm{~mm}$. A rotational speed of $350 \mathrm{rpm}$ and a milling time of $5 \mathrm{~h}$ were set. In order to obtain a highly crystalline product, the grounded powder was annealed at $T=550^{\circ} \mathrm{C}$ for $2 \mathrm{~h}$ under $\mathrm{H}_{2} \mathrm{~S}$ atmosphere. A $0.1 \mathrm{M} \mathrm{Cd}\left(\mathrm{CH}_{3} \mathrm{CO}_{2}\right)_{2}$ solution and $\mathrm{H}_{2} \mathrm{~S}$ (Air Liquide, 99.5\%) were used for precipitation of CdS. SnS was synthesized using the high-temperature solid-state reaction of the elements tin (Merck, 99.9\%) and sulfur (Fluka, 99.99\%) in an evacuated and sealed $\mathrm{SiO}_{2}$ ampoule.

\subsection{Structural and chemical characterization}

X-ray powder diffraction investigations as well as in-situ hightemperature X-ray diffraction experiments $\left(25-300^{\circ} \mathrm{C}, \mathrm{N}_{2}\right.$ atmosphere) were carried out with a RIGAKU SmartLab $3 \mathrm{~kW}$ system equipped with a K $\alpha 1$ unit (Johansson-type Ge crystal, $\mathrm{CuK} \alpha_{1}$ radiation, $\lambda=1.54060 \AA$ A). The diffraction data were obtained in Bragg-Brentano geometry over an angular range
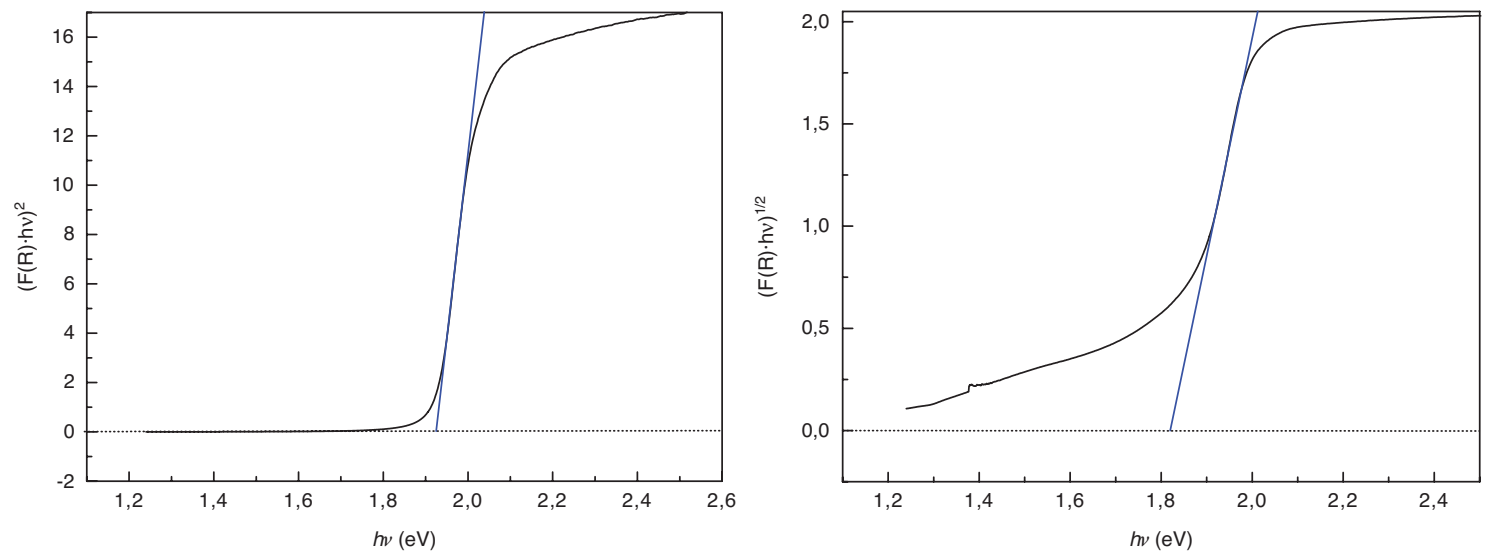

Fig. 11: UV/Vis spectra of $\mathrm{Ag}_{2} \mathrm{CdSnS}_{4}$ with Tauc plot determinations of the direct (left) and indirect (right) optical band gap. 
of $2 \theta=10-120^{\circ}$ for room temperature and $2 \theta=10-80^{\circ}$ for high-temperature measurements. Rietveld refinements [40] were performed using the program FULLPROF [41] by applying a pseudo-Voigt function. Backgrounds were fitted using a set of various background points with refinable heights. It should be mentioned that anisotropic strain broadening terms were used due to anisotropic reflection broadening.

Further details of the crystal structure investigation may be obtained from Fachinformationszentrum Karlsruhe, 76344 Eggenstein-Leopoldshafen, Germany (fax: +49-7247-808-666; e-mail: crysdata@fiz-karlsruhe. de, http://www.fiz-informationsdienste.de/en/DB/icsd/ depot_anforderung.html) on quoting the deposition numbers CSD-1979198 and CSD-1979199.

For the chemical characterization of $\mathrm{Ag}_{2} \mathrm{CdSnS}_{4}$, energy dispersive X-ray spectroscopy (EDX) using a DSM 982 GEMINI spectrometer (Carl Zeiss AG, Oberkochen, Germany) equipped with a XFlash $6 \mid 60$ detector (Bruker, Billerica, USA) were performed. For the determination of the sulfur content, an instrumental error of $5 \%$ is given. The EDX measurements were carried out at the Zentrum für Elektronenmikroskopie (ZELMI) of the TU Berlin. For the confirmation of the sulfur content, additional analyses were carried out using a FlashEA 1112 elemental analyzer (Thermo Scientific ${ }^{\mathrm{TM}}$, Waltham, USA). Hereby, a device error of $2 \%$ is assumed.

Thermoanalytical analysis (DTA) were carried out using a STA 7300 thermogravimeter (Hitachi, Chiyoda, Japan). These measurements were performed under nitrogen atmosphere up to $300^{\circ} \mathrm{C}$ with a heating and cooling rate of $3 \mathrm{~K} \mathrm{~min}^{-1}$; alumina crucibles were used as reference and sample container.

\subsection{UV/Vis spectroscopy}

The optical band gaps were determined by UV/Vis measurements using a V670 UV/Vis-NIR spectrometer (Jasco Deutschland GmbH, Pfungstadt, Germany). The spectra obtained in diffuse reflectance mode were converted into absorption spectra by the Kubelka-Munk function; the optical band gaps were received from the absorption spectra using the Tauc plot method [37, 38]. The standard deviation for $E_{\mathrm{g}}$ was estimated close to $0.05 \mathrm{eV}$. For sample preparation, $\mathrm{Ag}_{2} \mathrm{CdSnS}_{4}$ was mixed with a white standard $(\mathrm{MgO})$ in a mass ratio of 1:1.

Acknowledgements: Special thanks to the Zentrum für Elektronemikroskopie (ZELMI) of the TU Berlin giving access to the EDX measurements. EDX measurements were carried out by Rodrigo Beltran-Suito; combustion analysis was performed by Juana Krone (both TU Berlin). DTA and UV/Vis measurements were carried out by Dr. Nina Genz (TU Berlin). This project was supported by the German Science Foundation (DFG, LE 781/19-1).

\section{References}

[1] C. H. L. Goodman, J. Phys. Chem. Solids 1958, 6, 305-314.

[2] B. R. Pamplin, Nature 1960, 188, 136-137.

[3] B. R. Pamplin, J. Phys. Chem. Solids 1964, 25, 675-684.

[4] E. Parthé, K. Yvon, R. H. Deitch, Acta Crystallogr. 1969, B25, 1164-1174.

[5] S. R. Hall, J. T. Szymanski, J. M. Stewart, Can. Mineral. 1978, 16, 131-137.

[6] W. Schäfer, R. Nitsche, Mater. Res. Bull. 1974, 9, 645-654.

[7] A. F. Moodie, H. J. Whitfield, Acta Crystallogr. 1986, B42, 236-247.

[8] B. Lui, M. Zhang, Z. Zhao, H. Zeng, F. Zheng, G. Guo, J. Huang, J. Solid State Chem. 2013, 204, 251-256.

[9] I. D. Olekseyuk, O. V. Marchuk, L. D. Gulay, O. Y. Zhbankov, J. Alloys Compd. 2005, 398, 80-84.

[10] K. Ito, T. Nakazawa, Jpn. J. Appl. Phys. 1988, 27, 2094-2097.

[11] H. Katagiri, K. Saitoh, T. Washio, H. Shinohara, T. Kurumadani, S. Miyajima, Sol. Energy Mater. Sol. Cells 2001, 65, 141-148.

[12] J. Seol, S. Lee, J. Lee, H. Nam, K. Kim, Sol. Energy Mater. Sol. Cells 2003, 75, 155-162.

[13] R. Caye, Y. Laurent, P. Picot, R. Pierrot, C. Lévy, Bull. Minéral. 1968, 91, 383-387.

[14] Z. Johan, P. Picot, Bull. Minéral. 1982, 105, 229-235.

[15] H. Haeuseler, M. Himmrich, Z. Naturforsch. 1989, 44b, 1035-1036.

[16] C. D. Brunetta, J. A. Brant, K. A. Rosmus, K. M. Henline, E. Karey, J. H. MacNeil, J. A. Aitken, J. Alloys Compd. 2013, 574, 495-503.

[17] C. D. Brunetta, B. Karuppannan, K. A. Rosmus, J. A. Aitken, J. Alloys Compd. 2012, 516, 65-72.

[18] S. Greil, Untersuchungen an ternären und quaternären Kupfer-, Lithium- und Silbersulfiden mit Diamantstruktur. Dissertation, Universität Regensburg, Regensburg 2015.

[19] C. L. Teske, Z. Naturforsch. 1979, 34b, 544-547.

[20] O. V. Parasyuk, I. D. Olekseyuk, L. V. Piskach, S. V. Volkov, V. I. Pekhnyo, J. Alloys Compd. 2005, 399, 173-177.

[21] A. Ritscher, J. Just, O. Dolotko, S. Schorr, M. Lerch, J. Alloys Compd. 2016, 670, 289-296.

[22] H. Bärnighausen, MATCH Commun. Math. Chem. 1980, 9, 139-175.

[23] U. Müller, Z. Anorg. Allg. Chem. 2004, 630, 1519-1537.

[24] O. V. Parasyuk, A. O. Fedorchuk, Y. M. Kogut, L. V. Piskach, I. D. Olekseyuk, J. Alloys Compd. 2010, 500, 26-29.

[25] C. D. Brunetta, W. C. Minsterman, C. H. Lake, J. A. Aitken, J. Solid State Chem. 2012, 187, 177-185.

[26] F. P. Bundy, J. S. Kasper, J. Chem. Phys. 1967, 46, 3437-3446.

[27] G. Aminoff, XI. Z. Kristallogr. 1923, 58, 203-219.

[28] K. A. Rosmus, C. D. Brunetta, M. N. Srnec, B. Karuppannan, J. A. Aitken, Z. Anorg. Allg. Chem. 2012, 638, 2578-2584.

[29] WINXPOW (version 1.2), STOE \& Cie GmbH, Darmstadt (Germany) 2001.

[30] L. O. Brockway, Z. Kristallogr. 1934, 89, 434-441. 
[31] M. I. Aroyo, J. M. Perez-Mato, D. Orobengoa, E. Tasci, G. de La Flor, A. Kirov, Bulg. Chem. Commun. 2011, 43, 183-197.

[32] M. I. Aroyo, A. Kirov, C. Capillas, J. M. Perez-Mato, H. Wondratschek, Acta Crystallogr. 2006, A62, 115-128.

[33] M. I. Aroyo, J. M. Perez-Mato, C. Capillas, E. Kroumova, S. Ivantchev, G. Madariaga, A. Kirov, H. Wondratschek, Z. Kristallogr. 2006, 221, 15-27.

[34] O. V. Parasyuk, L. V. Piskach, I. D. Olekseyuk, V. I. Pekhnyo, J. Alloys Compd. 2005, 397, 95-98.

[35] J. W. Lekse, M. A. Moreau, K. L. McNerny, J. Yeon, P. S. Halasyamani, J. A. Aitken, Inorg. Chem. 2009, 48, 7516-7518.

[36] J. W. Lekse, B. M. Leverett, C. H. Lake, J. A. Aitken, J. Solid State Chem. 2008, 181, 3217-3222.
[37] J. Tauc, R. Grigorovici, A. Vancu, Phys. Stat. Sol. (b) 1966, 15, 627-637.

[38] J. Tauc, Mater. Res. Bull. 1968, 3, 37-46.

[39] G. E. Davydyuk, G. L. Myronchuk, I. V. Kityk, S. P. Danyl'chuk, V. V. Bozhko, O. V. Parasyuk, Opt. Mater. 2011, 33, 1302-1306.

[40] H. M. Rietveld, J. Appl. Crystallogr. 1969, 2, 65-71.

[41] J. Rodríguez-Carvajal, FulLPRoF, A Program for Rietveld Refinement and Pattern Matching Analysis, Satellite Meeting on Powder Diffraction of the $15^{\text {th }}$ International Congress of the IUCr, Toulouse (France) 1990, p. 127.

[42] S. Chen, A. Walsh, Y. Luo, J. Yang, X. G. Gong, S. Wei, Phys. Rev. B. 2010, 82, 195203-1-195203-8. 